\title{
The Relation between Initial Returns and Audits by the Big Four Accounting Firms
}

\author{
Jen-Sin Lee ${ }^{1}$, Yue Li ${ }^{2}$, Xin $\mathrm{Hu}^{3}$, Qi-An $\mathrm{Lu}^{4}$ \\ ${ }^{1}$ Department of Finance, I-Shou University, Taiwan \\ ${ }^{2}$ Institute of Taiwan Economy, Economic School, Nankai University \\ ${ }^{3}$ Department of Budget and Finance, Changan University \\ ${ }^{4}$ School of Economics and Management, Guangxi Normal University, Guilin, Guangxi, 541004, China \\ Correspondence: Jen-Sin Lee, Department of Finance, I-Shou University, Taiwan.
}

Received: February 27, 2017

Accepted: April 27, $2017 \quad$ Available online: June 7, 2017

doi:10.11114/aef.v4i4.2471

URL: https://doi.org/10.11114/aef.v4i4.2471

The research is financed by Collaborative Innovation Center for China Economy.

\begin{abstract}
This paper mainly explores the relation between initial returns and audits by the big four accounting firms (the Big Four) in China. The sample period is from January 2007 to December 2012 (the new accounting standards in China is implemented after January 2007 for integrating with the international standards), and selected 1,069 IPO firms listed in the Shanghai Stock Exchange and Shenzhen Stock Exchange in this paper.

Many previous studies have proposed the Informational Hypothesis, which states that the initial returns of IPOs being audited by the Big Four are lower than those IPOs being audited by other accounting firms. Oppositely, this paper proposes the Snap-up Hypothesis due to consider the IPOs in mainland China are characterized by "three lows,": the low reliability of audits being performed by non-Big Four, low proportion of IPOs audits being performed by the Big Four, and low balling ratio. These "three lows" features indicate that the Snap-up Hypothesis applies in the IPOs market of mainland China. In other words, the initial returns of the IPOs being audited by the Big Four are higher than those IPOs being audited by other accounting firms due to the Big Four have the superior reputations.

This paper further collects the trading volumes and the turnover ratio on the first day, and selects the Big Four audited IPOs by snap-up tide. As above mentioned, because the snap-up tide and raised stock prices on the first-day listing, investors may purchase the shares when offering and sell them on the first-day listing to obtain considerable profits.
\end{abstract}

Keywords: four accounting firms, initial return,Informational Hypothesis, Snap-up Hypothesis

\section{Introduction}

Initial public offerings (hereafter IPOs) are a critical research topic in financial and economic area. Previous studies related to IPOs have focused mainly on three aspects of IPOs, including short-term underpricing, hot-issue markets, and long-term underperformance. Beatty (1989), Michaely and Shaw (1995), Su and Fleisher (1999), Chen and Li(2004), Chi and Padgett (2005), Yang et al. (2007), X.Chang et al. (2008), Qiu et al. (2013), and Hu and Feng(2013) have discussed short-term IPOs discounts.

In previous studies, IPO short-term underpricing has been found to be an international phenomenon. In the stock markets of 39 countries, the average rates of initial return (hereafter IR) of IPOs are positive, and IPOs underpricing in China is the highest in the world (Tian, 2011). Because of the economic development of China and the rapid development of the Chinese stock market, investors and firm managers have focused increasing attention on the high underpricing in the Chinese stock market ${ }^{1}$.

\footnotetext{
${ }^{1}$ On Nov. 30, 2013, China Securities Regulatory Commission issued Opinions on Further Promoting the Reform of IPOS System, in which the Commission pointed out that it would strengthen restrictions against "IPOs speculation".
} 
The IRs of IPOs are also referred to as the extent of underpricing. This paper explores the relation between IRs and audits by the big four accounting firms (the Big Four) ${ }^{2}$.

Previous studies, including those by Rock (1986), Beatty and Ritter (1986), Teoh and Wong (1993), Beatty (1989), Michaely and Shaw (1995), and Lee et al. (2011), have found that audits performed by accounting firms with superior reputations may provide investors with more reliable financial information as well as help to reduce asymmetric information and investor risk. Association with the Big Four can signal to investors that investing in firms is safe, which can lower information asymmetry, investor risk, and IPO IRs. That is called "Lower Information Asymmetry Hypothesis" in the literature.

Because the IRs are calculated by $\left[\left(\mathrm{P}_{1}-\mathrm{P}_{0}\right) / \mathrm{P}_{0}\right]$, where $\mathrm{P}_{1}$ and $\mathrm{P}_{0}$ are the closing price on the first day of listing and the offering price respectively. It has to be noticed that lower information asymmetry will cause smaller decline of offering price $\mathrm{P}_{0}$ in the issue markets. Many empirical studies have supported this hypothesis, including the studies of Balvers et al. (1988), Beatty (1989), and Holland and Horton (1993), which examined IPOs in the USA and UK.

As the table 1 of descriptive statistics shows, the IRs of IPOs of the listed companies audited by Big Four CPA firms are higher, which may be caused by "three lows" characteristics of China IPOs market (the low reliability of audits performed by accounting firms other than the Big Four, low proportion of IPOs audits performed by the Big Four, and low balling ratio). Thus, this study proposes "Snap-up Hypothesis". These "three lows" cause investors to snap up shares offered by firms audited by the Big Four on the first day of listing and raise the closing price on the first day, causing the closing price to be much higher than the offering price, indicating high IPOs underpricing. It is worth noting that "Snap-up Hypothesis" will raise the closing price $\mathrm{P}_{1}$ on the first day in the secondary markets.

Therefore, the audit firm reputation may have the effects, which are "Lower Information Asymmetry Hypothesis" and "Snap-up Hypothesis", the former is occurred when lowering the decline of offering price in the issue market; and the latter is occurred when raising the closing priceon the first day in the secondary market. The prior studies fines the effect of "Lower Information Asymmetry" is dominated in most IPOs markets, but this study fines the effect of "Snap-up Hypothesis" is dominated in China IPOs market. Few empirical studies have been conducted on this hypothesis. However, Chang et al. (2008) empirically studied this hypothesis by examining listed firms in Australia. They found that the IRs on IPOs of firms associating with high quality auditors were generally higher than those of firms associating with common auditors. These results support the Snap-up Hypothesis.

Since 2004, scholars in mainland China have performed many studies on the relation between IPOs underpricing and auditor reputation for Chinese enterprises. However, the results of these studies have varied. Chen and $\mathrm{Li}(2004)$ as well as Zeng and Shi (2011) found that auditing by accounting firms with superior reputations may significantly lower the extent of underpricing. Moreover, Liu and Tan(2009) as well as Wang, Xin, and Yang(2009)found in their studies on the Shanghai and Shenzhen Stock Exchanges that IPOs of firms audited by the Big Four were more underpriced. In other words, these studies support the Informational Hypothesis. However, the studies by Qiu et al.(2013) on small- and medium-sized enterprise(SME) boards concluded that IPOs of firms audited by accounting firms with superior reputations were not more underpriced. However, Hu and Feng(2013) found that high quality auditors could increase the IRs of IPOs. Furthermore, Song,Tan, and Yi (2014) divided the IRs of IPOs into two parts, underpricing from issue markets ${ }^{3}$ and overvaluation from secondary markets, and found through empirical study that the reputation of underwriters positively correlated with IPO underpricing. The results of these empirical studies thus support the Snap-up Hypothesis.

The theoretical arguments and various empirical results regarding the relation between IPOs underpricing and auditor reputation for Chinese enterprises make this topic appealing for researchers. Although scholars dispute which hypothesis more accurately reflects the relation between IPOs underpricing and auditor reputation, this paper argues that in practice both hypotheses are true to an extent and produce corresponding effects. On this basis, this paper contends that the primary issue is not which of the two hypotheses is true but rather which of the hypotheses is more dominant. This paper selects IPOs in mainland China as the object of study and discusses the relation between IRs and audits by the Big Four.

\footnotetext{
${ }^{2}$ There were five Big Four joint ventures in Chinese Mainland, PwC Zhongtian, DT Huayong, E\&Y Huaming, E\&Y Dahua and KPMG Huazhen before 2008. However after the consolidation of E\&Y Huaming and E\&Y Dahua in December 2008, the Big Four joint ventures in Chinese Mainland are PwC Zhongtian, KPMG Huazhen, DT Huayong and E\&Y Huaming, respectively.

${ }^{3}$ The mainstream is that the initial return is also called IPOs underpricing, refers to the phenomenon that the close price is higher than the offering price on the first day of listing. While some scholars thought that the initial return and IPO underpricing are totally different concepts. In this paper we take the mainstream point.
} 
This paper uses 1,069 A-share IPOs in the Shanghai and Shenzhen Stock Exchanges from January 2007 to December 2012 as empirical samples to discuss the relation between IRs and audits by the Big Four. Compared with other major IPOs markets, the IPOs market in mainland China is characterized by "three lows," which is explained as follows.

First, compared with other major IPOs markets, the proportion of listed firms audited by the Big Four is low in the IPO market in mainland China. For example, among the 1,069 IPOs firms in our study, only 40 were audited by the Big Four, indicating a proportion of $3.74 \%$. This proportion is extremely low compared with other major stock markets. For example, Lee et al. (2011) found that 383 of the 434 IPOs firms in Taiwan were audited by the Big Four, indicating a proportion of $88.25 \%$. Additionally, Frankel, Johnson, and Nelson (2002) found that $90.44 \%$ of listed firms were audited by the Big Four for IPOs in the USA. Furthermore, Fan and Wong (2005) found proportions of $88.32 \%$ in Indonesia, $74.86 \%$ in Malaysia, and $72.37 \%$ in Korea. Finally, Chang et al. (2008) found a proportion of $46 \%$ in Australia, which is lower than those in the aforementioned countries but higher than that in mainland China.

Second, compared with those in other major IPO markets, the financial reports of listed firms in the IPO market in mainland China are less reliable. The reliability of the financial reports of listed firms in mainland China has been widely criticized (Cai et al., 2008; Lin and Lin, 2009; Ferri and Liu,2010; the credit rating and certification center of the research institute of the Ministry of Commerce, 2013, 2014). According to the Appraisal Report on Financial Safety of Non-financial Listed Firms in China in 2013(2014), jointly released by the credit rating and certification center of the research institute of the Ministry of Commerce and the Economy Web of China Review (a monthly journal), 766 of 2,230 (744 of 2,213) listed firms were suspected offorging financial statements, representing $34.35 \%(34.32 \%)$ of the samples. This report also stated that false financial statements of listed firms in mainland China are a serious problem. For example, 96 real estate firms in mainland China (over 70\%) are suspected of forging financial records. Cai et al. (2008) asserted that financial statements audited by the Big Four are highly reliable, whereas those audited by other accounting firms are not sufficiently reliable.

Third, the IPO market of mainland China tends to be a hot-issue market. The average balling ratio is very low (1.2\%), and the minimum balling ratio value is only $0.66 \%$. In other words, only 6.6 of every 1,000 applicants succeed in subscribing.

Based on the previous analysis, the characteristics of the IPO market in mainland China can be summarized as the "three lows". These characteristics are different from the features of the IPO market in Australia studied by Chang et al. (2008). Would the effect and influence of the two aforesaid hypotheses differ in such a market? Which hypothesis, the Informational Hypothesis or Snap-up Hypothesis, would dominate in the IPO market of mainland China? These issues should be examined through empirical studies.

Compared with previous studies on the effect of auditor reputation in mainland China, this paper differs in the following ways.

First, as stated previously, this paper attempts to determine which hypothesis, the Informational Hypothesis or Snap-up Hypothesis, dominates in explaining the "three lows" of the IPO market of mainland China.

Second, this paper analyzes whether the dominance of the Informational Hypothesis or Snap-up Hypothesis under various market conditionshas different effects. This paper performs a robustness test based on the various market states defined by Lee et al. $(2011,2013)$. In addition to market state, robustness tests are also performed for factors such as offering scale andexchange board division.

Finally, compared with previous studies, the samples chosen in this paper are characterized by the following: (a). the sample period covers many market states; (b). a large sample size is included in this study; (c). the sample period occurs after the implementation of the new accounting standards. Specifically, the sample period in this paper is May 2006 to August 2013 ( 88 months in total), which includes the bull (23 months), bear (23 months), and range-bound markets (26 months $)^{4}$. In addition, compared with other studies, the sample period in this paper covers more market states and has alarger samplesize of IPO firms. For example, Gao (2010) studied only 217 IPO firms from July 2006 to April 2008, when the Shanghai and Shenzhen Stock Exchange 300 Index was in a bull market state. Moreover, Qiu et al. (2013) studied only 223 IPO firms from June 2006 to December 2008, when the Shanghai and Shenzhen Stock Exchange 300 Index was in a bull market state. Additionally, Hu and Feng (2013) studied only 517 nonfinancial firms from July 2009 to April 2011, when the Shanghai and Shenzhen Stock Exchange 300 Index was in a bear market state. New accounting standards were implemented in January 1, 2007 for mainland China, and the focus of this paper is the relation between IRs and audits by the Big Four. This paper analyzed samples after January 2007 to avoid sample heterogeneity caused

\footnotetext{
${ }^{4}$ As stated above, the period studied in this paper is from January 2007 to August 2013 (totally 88 months). However, as it needs 8 months to distinguish market states, the actual period studied is from January 2007 to December 2012 (totally 72 months).
} 
by various accounting standards. Tian (2011) studied 1,377 IPO firms from January 1992 to December 2004; although their sample was sufficiently large, the sample period did not include the period when the new accounting standards were implemented. Song, Tan, and Yi (2014) studied firms from September 2006 to December 2011; part of their sample period thus occurred before the implementation of the new accounting standards (such a period may cause significant heterogeneity of samples and thus errorsin empirical results).

To ensure the robustness of the empirical results, this paper performs the following four robustness tests: empirical analysis using market-adjusted IR rather than raw IR as the dependent variable and analyses based on exchange board division, market state division, and offering scale division.

The main findings are as follows: The IPOs in mainland China are characterized by the "three lows," the low reliability of audits performed by accounting firms other than the Big Four, low proportion of IPOs audits being performed by the Big Four, and low balling ratio. Furthermore, in mainland China, the IPOs firms being audited by high-credibility accounting firms are found to cause snap-up tide. Because of the previously mentioned snap-up tide and raised stock prices on the first day of listing, investors may purchase the shares of firms at the time of offering and then sell them on the first day of listing to obtain considerable profits. Therefore, this paper concludes that the Snap-up Hypothesis is dominant in explaining the features of IPOs in mainland China. This conclusion differs from the results of previous studies (i.e., the Informational Hypothesis is dominant in explaining the features of IPOs in mainland China). However, our paper does not deny the application of the Informational Hypothesis to the IPOs market of mainland China, but we find that the Snap-up Hypothesis is dominant in explaining the features of this market. In addition, this paper also attempts to perform four robustness tests, which show no significant differences in the empirical results.

The sections of this paper are arranged as follows: the second chapter includes a description of the hypothesis deduction and empirical model proposals; the third chapter includes information on market state division and data analysis; the fourth chapter discusses the empirical results as well as the hypothesis and robustness tests; andthe fifth chapter provides the significant findings of this paper and discusses their implications.

\section{Hypothesis Deduction and Empirical Models}

\subsection{Market State and Initial Return}

Lee, Jiang, and Indro (2002) found that market states could affect investor sentiment and behavior. Specifically, in bull markets, investor sentiments are positive, and investors expect high excess returns in the future. By contrast, in bear markets, investors are non-positive and expect low excess returns in the future. Ljungqvist, Nanda, and Singh (2001) found that IPO IRs varied among market states (cold- or hot-issue). As previously mentioned, Lee et al. (2011) studied the factors influencing the IRs of IPO firms in Taiwan and found that the auditor reputation effect was significant in range-bound markets but not in bear or bull markets. Furthermore, they found that market momentum was higher in bull markets than range-bound and bear markets. Wang and Zhang (2005) asserted that in the mainland Chinese share market, the general market trend also influenced investor behavior.

Therefore, in various market states, investors have various investment sentiments, and the effect of various factors on IRs may also vary. In this paper, the impact of auditor reputation on IRs in mainland China is studied in various market states to test the robustness of the empirical results.

\subsection{Hypothesis Deduction}

Previous studies, including those by Rock(1986), Beatty and Ritter (1986), Teoh and Wong (1993), Beatty (1989), Michaely and Shaw (1995), and Lee et al. (2011), have found that audits performed by accounting firms with superior reputations may provide investors with more reliable financial information as well as help to reduce asymmetric information and investor risk. Association with the Big Four can signal to investors that investing in firms is safe, which can lower information asymmetry, investor risk, and IPO IRs. This is referred to as the Informational Hypothesis or the auditor reputation effect. This hypothesis is summarized in the flow chart shown in Figure 1.

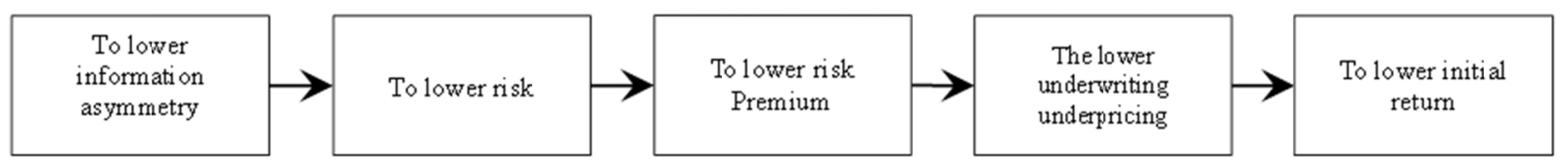

Figure 1. Flow chart of informational hypotheses

If the flow chart in Figure 1 is supported, then the corresponding hypothesis is as follows.

Hypothesis 1:The Informational Hypothesis, in other words, the hypothesis that the IRs of IPOs audited by the Big Four is lower than that of IPOs audited by other accounting firms.

However, as discussed previously, audits of IPOs in mainland China are distinct from audits in mature markets. Cai et 
al.(2008) asserted that the reliability of financial reports of listed firms in mainland China has been criticized. The credit rating and certification center of the research institute of the Ministry of Commerce $(2013,2014)$ stated that false financial statements of listed firms in mainland China are a serious problem. This paper also finds that, in mainland China, the proportion of listed firms audited by the Big Four is very low. Compared with other major IPO markets, the characteristics of the IPO market in mainland China can be summarized as "three lows," the low reliability of audits performed by accounting firms other than the Big Four, low proportion of IPO audits performed by the Big Four (the IPO market share of the Big Four in mainland China is only 3.74\%), and low balling ratio (the average balling ratio only $1.2 \%$ ). These "three lows" cause investors to snap up shares offered by firms audited by the Big Four on the first day of listing and raise the closing price on the first day, causing the closing price to be much higher than the offering price, indicating high IPO underpricing. This is referred to as the Snap-up Hypothesis. This hypothesis is summarized in the flow chart shown in Figure 2.

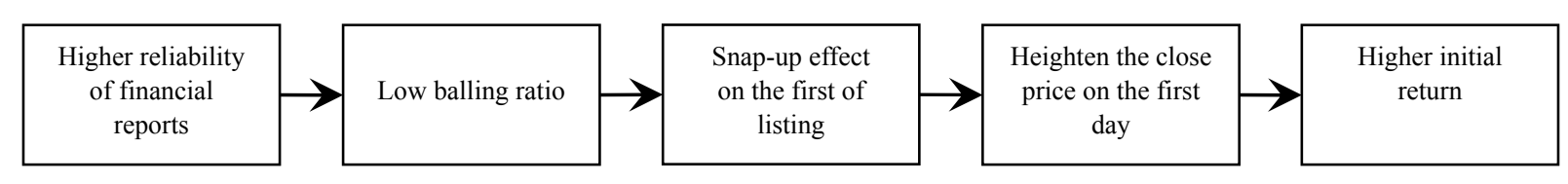

Figure 2. Flow chart of snap up hypotheses

If the flow chart in Figure 2 is supported, then the corresponding hypothesis is as follows.

Hypothesis 2:The Snap-up Hypothesis, in other words, the hypothesis that the IRs of IPOs audited by the Big Four are higher than those of IPOs audited by other accounting firms.

\subsection{Empirical Model}

This paper mainly studies the impact of audits by the Big Four on IRs of IPOs, with reference to the empirical model designed by Lee et al. (2011). The original model of Lee et al. (2011) contained the variables of insider stockholding and block holder proportions. However, because no data are available on these two variables for mainland China, these two variables are excluded from our study. In addition, considering the high proportion of individual investors in mainland China, which may be easily affected by market sentiment, a new variable, the average IR $(A I R)$ of individual shares, is added in this paper.

Our model is as follows:

$$
\begin{aligned}
& I R_{i}^{m}=\alpha^{m}+\beta_{1}^{m} A R 4_{i}+\beta_{2}^{m} R+\beta_{3}^{m} A I R_{i}+\beta_{4}^{m} M+\beta_{5}^{m} L T_{i}+\beta_{6}^{m} B R_{i} \\
& +\beta_{7}^{m} L N_{i}+\beta_{8}^{m} \operatorname{SIZE~}_{i}+\mathrm{e}_{i}
\end{aligned}
$$

In the model, IR is measured by raw IR $(R I R)$ and market-adjusted IR $(M A I R)$ in the robustness test; $\mathrm{m}$ represents various market states, including bull, bear, and range-bound; $A R 4$ is a dummy variable representing audits by the Big Four; $R, A I R, M, L T, B R$, and SIZE represent market risk, average IR of individual shares, market momentum, listing days (days between the offering day and listing days), balling ratio, and size of issuance, respectively. The data used here is cross-section data.

\subsection{Variables}

\subsubsection{Initial Return, Raw Initial Return, and Market Adjusted Initial Return}

In the literature, $I R$ is mainly expressed as raw IR $(R I R)$ and market adjusted IR $(M A I R)$, respectively. RIR represents the difference between the closing price on the first day of listing and the offering price, whereas MAIR represents the return after deducting the market index return. The formulas for both are as follows:

$$
R I R=\left[\left(P_{\mathrm{t}}-P_{0}\right) / P_{0}\right] \times 100 \%
$$

In this equation, $P_{t}$ and $P_{0}$ are the closing price on the first day of listing and the offering price, respectively. 


$$
M A I R=\left[R I R-\left(I_{t}-I_{0}\right) / I_{0}\right] \times 100 \%
$$

In this equation, $I_{t}$ and $I_{0}$ are the market index on the first day of listing and the market index on the offering day, respectively.

The dummy variable representing audits by the Big Four (AR4):

In the literature, two main hypotheses have been proposed concerning the relation between IRs and audits by the Big Four. The two main hypotheses are the Informational Hypothesis and the Snap-up Hypothesis. The dummy variable AR4 is set to 1 for IPOs audited by the Big Four and 0 for IPOs audited by other accounting firms.

\subsubsection{Market Risk}

Market risk reflects future uncertainty. Derrien and Womack (2003) as well as Lee et al. (2011) used the standard deviation of daily returns of the market index between the offering day and listing day to measure market risk, finding that the market risk was significantly and positively correlated with IRs. With reference to the arrangement of Lee et al. (2011), this paper uses the standard deviation of the daily returns of the market index between the offering day and listing day to measure market risk, and the formula is as follows:

$$
R_{i}=\sqrt{\frac{\sum_{t=0}^{T}\left(r_{t}-\bar{r}\right)^{2}}{D}}
$$

In Formula (4), $R i$ represents the market risk of firm $i$, and $t=0, t=T$, and $r_{\mathrm{t}}$ represent the returns of market index on the offering day, the listed day, and day $t$, respectively. $r$ represents the average value of the market returns between the offering day and listing day, and $D$ represents the number of trading days from the offering day to the listing day.

\subsubsection{Average Initial Return of Shares}

The average IR of shares represents the average value of IRs on new shares during a given period and reflects market sentiment and investor expectation of IRs in the market. In this paper, this variable is used as a reference for the impact of IRs of new shares.

$$
A I R=\sum_{t=0}^{t=T} \sum_{i=0}^{i=N} I R_{i} / N
$$

In Formula (5), $I R_{i}$ represents the IRs of firm $i$, and $N$ is the total number of listed firms between $t=0$ and $t=T$.

\subsubsection{Market Momentum}

In the literature, such as the studies of Kunz and Aggarwal (1994), Loughran and Ritter (2002), Lyn and Zychowicz (2003), Derrien and Womack (2003), and Lee et al. (2011) a more prosperous market before an IPO has been found to increase the IRs. Lee et al. (2011) found that various market states have different effects on market momentum. In this paper, market momentum is calculated using the method developed by Lee et al. (2011). The formula is as follows:

$$
M_{i}=\left[\prod_{t=0}^{T}\left(1+r_{t}\right)\right]-1
$$

In Formula (6), $M_{i}$ represents the market momentum of firm $i$, and $r_{t}$ represents the market index returns on day $t^{5}$. Formula (6) shows that when the market index trends upward, the market momentum $(M)$ is positive, and when the market index trends downward, the market momentum is negative. The data of the paper is cross-sectional data and not panel data. Market return is not the same for all firms.

\subsubsection{Listing Days, Balling Ratio, and the Size of Issuance}

Listing Days refer to the number of days between the offering day and listing day. The balling ratio reflects the hotness of new shares among investors; a lower balling ratio indicates higher hotness. The size of issuance represents the

\footnotetext{
${ }^{5}$ The formula of $r_{i}$ is as follows: $r_{i}=\left(P_{i-}-P_{i-1}\right) / P_{i-1}$, there $P_{i-1}$ and $P_{i}$ represents the market index on the day $i-1$ and day $i$, respectively.
} 
offering scale of the listed firm and reflects the scale of funding through listing. In this paper, with reference to the arrangement of Lee et al. (2011), the natural logarithm of the size of issuance is calculated to mitigate the problem of scale of various independent variables.

\section{Data and the Distribution ofMarket States}

\subsection{Source of Data}

On February 15, 2006, the Ministry of Finance held a news conference on the release of accounting and auditing standards in Beijing, including 39 accounting standards for enterprises and 48 auditing standards for certified public accountants. The accounting standards for enterprises have been implemented by listed firms since January 1, 2007 to consolidate the accounting system inmainland China with the international systems. The auditing standards for certified public accountants have been implemented since January 1, 2007. Considering the change of these standards, this paper uses firms listed from January 2007 to December 2012 as samples. The data on the listed firms are sourced from the Taiwan Economic Journal and RESSET database. The Shanghai and Shenzhen 300 Index is sourced from the website of the Shanghai Stock Exchange. The ranking information of accounting firms is sourced from the website of the Chinese Institute of Certified Public Accountants.

The samples in this paper cover 12 industries. $^{6}$ After excluding a few samples with incomplete data, a total of 1,069 IPO firms are selected, including firms listed in the A-share markets of Shanghai and Shenzhen Stock Exchanges. ${ }^{7}$ Therefore, 119 firms are listed in the Shanghai Stock Exchange, 950 are listed in the Shenzhen Stock Exchange, the IPO of 201 firms was during a bull-market period, and the IPO of 868 firms was during a bear-market period.

\subsection{Descriptive Statistics and Correlation Coefficients}

Table 1 provides a list of statistical values of main variables and shows that the IRs of IPOs in mainland China have the following four characteristics: First, the value of IRs of IPOs in mainland China is high: The RIR is up to $59.40 \%$, the MAIR is up to $59.55 \%$, and a high return of nearly $60 \%$ can be obtained under average listing days $(L T)$ of 12 . Second, the IRs of IPOs inmainland China seem to be trending downward: the sample period in this paper is from January 2007 to December 2012 (including A-share firms listed in the Shanghai and Shenzhen Stock Exchanges), and the periods studied by Chan et al. (2004) and Chen et al. (2004) are from 1993 to 1998 and 1992 to 2000 (A-share market), respectively. The average IRs of the periods studied by Chan et al. (2004) and Chen et al. (2004)are 178\%. The IRs of IPOs in mainland China seem to be trending thus downward.

Third, some negative IRs are found, but the ratio of these returns is not high. Among the 1,069 listed firms studied, 144 firms had negative RIRs, and 136 had negative MAIRs, yielding $13.47 \%$ and $12.72 \%$, respectively. These two ratios are not high, and the average values of both the RIR and MAIR are nearly $60 \%$, indicating that IPOs inmainland China are worthy of investor subscription during the offering phase. Finally, the RIR and MAIR are similar, including their average values, medians, maximum values, minimum values, and standard deviations, and no statistical difference is found between various $R I R$ values and corresponding $M A I R$ values.

The average IR of IPOs audited by the Big Four (AR4) is $79.98 \%$, significantly higher than the RIR of $59.4 \%$, indicating the possibility of increasing IRs by association with the Big Four. In other words, Hypothesis 2 seems to besupported, and the Snap-up Hypothesis is dominant in the IPO market of mainland China.

Moreover, in terms of the balling ratio $(B R)$, the following two features are found: First, the IPO market of mainland China tends to be a hot-issue market. The average $B R$ is very low (1.2\%), and the minimum $B R$ value is only $0.66 \%$. In other words, only 6.6 of every 1,000 applicants can succeed in subscribing. Second, the possibility of unsalable IPO shares is low in mainland China. The maximum $B R$ in the samples is $65.52 \%$, less than 1, indicating that unsalable IPOs resulting from a lack of subscribers in China is unlikely.

In this paper, the correlation coefficients among independent variables and variance inflation factor (VIF) are evaluated to avoid multicollinearity among independent variables. Furthermore, the Pearson correlation coefficients among the independent variables are all much lower than 0.7 and insignificant, and the VIF values are all much lower than 10 . Multicollinearity is thus not a problem in this paper. Table 2 shows the correlation coefficients among the independent variables.

\footnotetext{
${ }^{6}$ No firm in the financial or insurance industries was listed from January 2007 to December 2012.

${ }^{7}$ No new B-share IPOs in the Shanghai and Shenzhen Stock Exchanges are found from January 2007 to December 2012.
} 
Table 1. Descriptive statistics of variables

\begin{tabular}{llllllllll}
\hline & $\begin{array}{l}R I R \\
(\%)\end{array}$ & $\begin{array}{l}\text { MRIR } \\
(\%)\end{array}$ & $\begin{array}{l}\text { RIR4 } \\
(\%)\end{array}$ & $\begin{array}{l}R \\
(\%)\end{array}$ & $\begin{array}{l}A I R \\
(\%)\end{array}$ & $\begin{array}{l}M \\
(\%)\end{array}$ & $\begin{array}{l}B R \\
(\%)\end{array}$ & $\begin{array}{l}L T \\
(\text { days })\end{array}$ & SIZE \\
\hline Mean & 59.40 & 59.55 & 79.98 & 1.53 & 58.58 & -0.15 & 1.20 & 12.11 & 20.34 \\
Median & 34.57 & 34.50 & 47.88 & 1.34 & 37.86 & -0.24 & 0.66 & 11.00 & 20.24 \\
Max & 626.74 & 626.07 & 626.74 & 4.50 & 519.51 & 22.56 & 65.52 & 50.00 & 25.43 \\
Min & -26.33 & -23.43 & -23.16 & 0.41 & -15.87 & -23.27 & 0.01 & 7.00 & 18.53 \\
S.D. & 79.48 & 78.23 & 110.41 & 0.68 & 69.76 & 6.01 & 2.77 & 4.11 & 0.87 \\
\hline
\end{tabular}

Note: RIR is rawIR; MAIR is market adjusted IR; RIR4 represents rawIR of those financial reports audited by the Big Four; $R$ represents market risk, the formula is as follows: $R_{i}=\sqrt{\sum_{i=0}^{T}\left(r_{t}-\bar{r}\right)^{2} / D}, R i$ represents the market risk of firm $i$, and $t=0, t=T$, and $r_{\mathrm{t}}$ respectively represents the return of market index on the offering day, the listed day and day $t$, $\bar{r}$ represents the average value of the market return between offering day and listed day, and $D$ represents the number of trading days from the offering day to the listed day; $A I R$ represents the average of IR, ${ }^{A I R=\sum_{t=0}^{t=T} \sum_{i=0}^{i=N} I R_{i} / N}, I R_{i}$ represents IR of firm $i$, and $N$ is the total number of listed firms between $t=0$ and $t=T ; M$ represents market momentum, and the formula is as follow: $M_{i}=\left[\prod_{t=0}^{T}\left(1+r_{t}\right)\right]-1 ; B R$ is balling ratio; LTrefers to the number of days from the offering day to the listed day; SIZE takes the natural logarithm of the offering size.

Table 2. Correlation Coefficient

\begin{tabular}{cccccccc}
\hline & $A R 4$ & $R$ & $A I R$ & $M$ & $B R$ & $L T$ & SIZE \\
\hline$A R 4$ & 1 & & & & & & \\
$R$ & 0.03 & 1 & & & & & \\
$A I R$ & -0.01 & 0.36 & 1 & & & & \\
$M$ & 0.01 & -0.12 & 0.17 & 1 & & & \\
$B R$ & 0.05 & -0.18 & -0.18 & -0.02 & 1 & & \\
$L T$ & 0.03 & 0.22 & 0.03 & 0.24 & -0.01 & 1 & \\
$S I Z E$ & 0.41 & -0.12 & -0.25 & -0.01 & -0.24 & -0.01 & 1
\end{tabular}

Note: In Table 2, AR4R, AIR,M,BR,LT and SIZErepresents dummy variable representing audit by the Big Four, market risk, average IR of individual share, market momentum, balling ratio, SIZE takes the natural logarithm of the offering size.

\subsection{Market State Division Method}

Pagan and Sossounov (2003) divided market states into bull and bear markets. Lee et al. (2011) and Lee et al. (2013) further developed this division method and added range-bound markets. In this paper, the modified division method is used, and the market states are divided into the bull, bear, and range-bound markets. The process is as follows.

\section{Step 1: Determine Peak and Trough}

Peak and trough refers to the highest and lowest point during a given period. According to a study by Pagan and Sossounov, if the conditions in Formula (7) are met, then position $\mathrm{P}_{\mathrm{t}}$ is referred to as peak:

$$
\left[P_{t-8}, \ldots, P_{t-1}<P_{t}>P_{t+1}, \ldots, P_{t+8}\right]
$$

In the previous formula, $P_{t}$ represents the market index corresponding to period $t$. Formula (7) represents market index $P_{t}$, which should be higher than the market indexes in the previous eight consecutive months and following eight consecutive months. If $P_{t}$ meets these conditions, the position of $P_{t}$ is referred to as a peak. Similarly, if the conditions in 
Formula (8) are met, then position $P_{t}$ is called trough:

$$
\left[P_{t-8}, \ldots, P_{t-1}>P_{t}<P_{t+1}, \ldots, P_{t+8}\right]
$$

In the previous formula, $P_{t}$ represents the market index of month $t$. Formula (6) represents market index $P_{t}$, which should be lower than the market indexes in the previous eight consecutive months and the market indexes in the following eight consecutive months. If $P_{t}$ meets these conditions, the position of $P_{t}$ is referred to as a trough. For the purpose of determining a peak and trough, the previous and following eight consecutive months should be checked based on the assertion by Pagan and Sossounov (2003) that the cycle of the US stock market should exceed 15 months.

\section{Step 2: Determine Bull and Bear Markets}

A bear market refers to a continuous downward market trend of the market witha sufficient accumulative drop and downward duration. A bear market occurs when the following three conditions are met: First, the market transitions from peak to trough. Second, the accumulative drop is more than $20 \%$ in stock index values. Third, during the period from peak to trough is not shorter than 4 months. When the market reaches the trough, the downward trend ends, and the market rises. The 4-month durational requirement was determined by Pagan and Sossounov (2003), Lee et al. (2011), and Lee et al. (2013) with reference to Hamilton (1919) and Dow Theory (developed by Charles Dow), and verified by empirical analysis of the US stock market. Edwards et al. (2003) also used this 4-month durational requirement.

Similarly, a bull market refers to a continuous upward trend of the market, with a sufficient accumulative rise and upward duration. A bull market occurs when the following three conditions are met: First, the market transitions from trough to peak. Second, the accumulative rise is more than $20 \%$ in stock index values. Third, the period from trough to peak is not shorter than 4 months. When the market reaches to the peak, the upward trend ends, and the market drops.

The previous two steps were developed by Pagan and Sossounov (2003), with two major modifications made by Lee et al. (2011) and Lee et al. (2013): First, a range-bound market was added; second, the classification of a bull, bear and neutral market are robust with a window length of 8 to 10 months.

\section{Step 3: Determine Range-Bound Markets}

After determining bull and bear markets, the remaining parts that cannot be defined as bull or bear markets are called range-bound markets in this paper. Katsenelson (2007) mentioned that when stock prices were narrow in valuation, the market was range-bound. Using Katsenelson's definition, this period is defined as a range-bound market in this paper.

\subsection{Results of Market State Division}

The sample period in this paper is from January 2007 to December 2012, and the samples are firms listed in the A-share market of the Shanghai and Shenzhen Stock Exchange. The Shanghai and Shenzhen 300 Index is thus used as a substitute for the market index. ${ }^{8}$ According to the studies by Lee et al. (2011) and Lee et al. (2013), 8 months is required before and after the study period; our market index selection period is thus from May 2006 to August 2013, covering 88 months. The bull market spans more than three intervals and covers 31 months, constituting $35.62 \%$ of total samples. Thebear market spans more than three intervals and covers 48 months, constituting $55.17 \%$ of total samples. The range-bound market spans more than one interval and covers 8 months, constituting $9.19 \%$ of total samples. In the intervals used in the empirical model, the bull market covers 23 months, constituting $32 \%$ ofthe total samples, with an average market return of $10 \%$. The bear market covers 48 months, constituting $68 \%$ of the total samples, with an average market return of $-5 \%$. The empirical model contains no range-bound market. The market state division is shown in Figure 2, and the information on the market state division is summarized in Table 3. ${ }^{9}$

\footnotetext{
${ }^{8}$ The Shanghai and Shenzhen 300 Index is a share market index calculated using 300 A-shares in the Shanghai and Shenzhen Stock Exchanges. These samples cover approximately $60 \%$ of the market value of these two markets and are highly representative.

${ }^{9}$ Here, the average return of the market under various market states is equal to the average value of the market returns of all months covered by such states.
} 


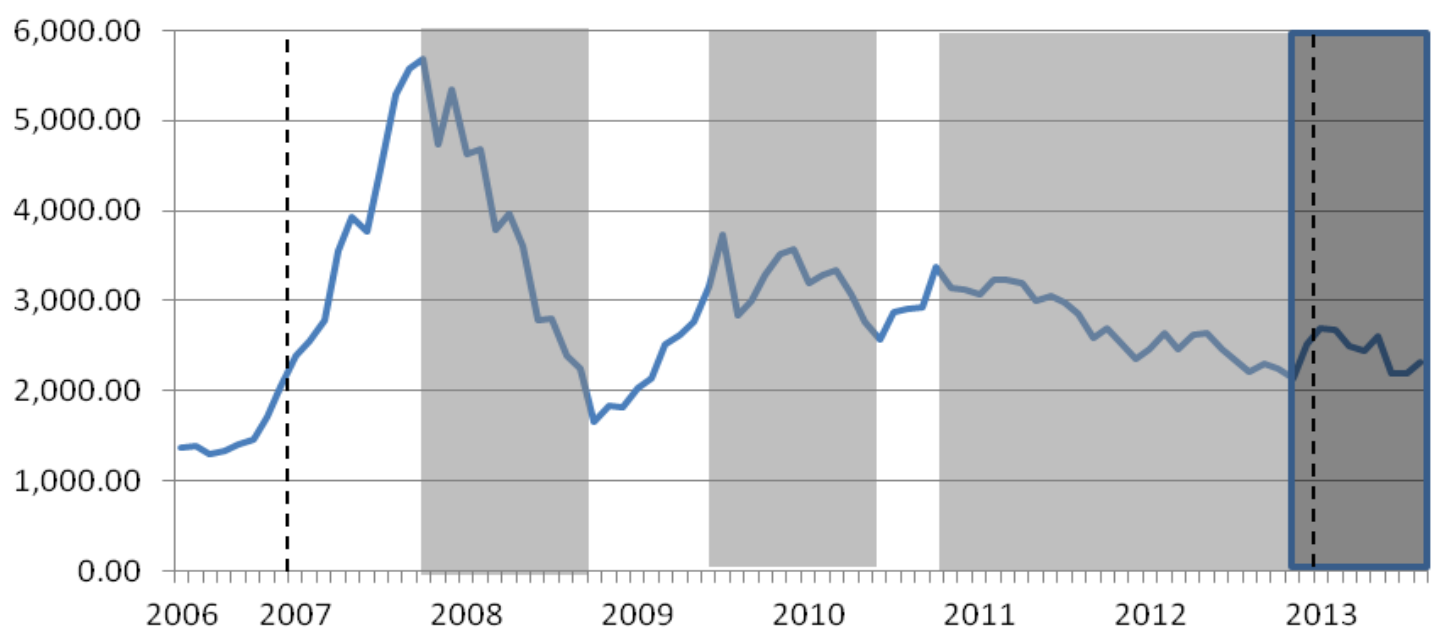

Figure 3. Result of market states division

Note: Fig. 3 is a bar graph of market states, the horizontal axis represents time (months), and the vertical axis represents the market index (CSI 300 Index).In order to divide the market states, Fig.3shows the change of the market index from May 2006 to August 2013, but the market index used in the empirical model is from January 2007 to December 2012. Thus the figure divides empirical sample and full sample with line of dashes. Within two dotted lines are the empirical part, white is bearish market states, dark state is bullish market states, light gray is the range-bound market state.

\section{Empirical Results and Robustness Tests}

The empirical results of this paper are summarized in Table 3, and Table 3 shows the empirical results of the effect of Big Four auditing (AR4). The results show that Hypothesis 2 is accepted. In other words, the Snap-up Hypothesis is dominant in the IPO market of mainland China. Therefore, the IRs of IPOs being audited by the Big Four are higher than those IPOs being audited by other accounting firms. The result is as follows.

Table 3 shows that the coefficient of AR4 is 0.63 , which is significant at the $1 \%$ level. The coefficient of AR4 is significantly positive, which indicates that audits by the Big Four can significantly increase the IRs of the firms audited, showing that hypothesis 2 is accepted. In other words, according to the samples in this paper, we find that the Snap-up Hypothesis is dominant, indicating that the hypothesis that "the IRs of IPOs audited by the Big Four are higher than those of IPOs audited by other accounting firms" is accepted.

The previous findings support that the Snap-up Hypothesis is dominant in the mainland Chinese IPO market, indicating that IRs increase if IPOs are audited by the Big Four, which have superior reputations compared with local accounting firms. This finding contrasts with the results of studies conducted in other IPO markets, which have indicated that the Informational Hypothesis is dominant, meaning that the IRs decrease if IPOs are audited by the Big Four. Studies by Teoh and Wong (1993), Beatty (1989), Michaely and Shaw (1995), and Lee et al. (2011) have reached this conclusion.

Table 3. Empirical Results

\begin{tabular}{ll}
\hline Dependent Variable: $R I R$ & \\
\hline $\mathrm{C}$ & 4.32 \\
& $(10.04)^{\mathrm{c}}$ \\
AR4 & 0.63 \\
& $(6.90)^{\mathrm{c}}$ \\
RISK & 9.27 \\
& $(3.49)^{\mathrm{c}}$ \\
AIR & 0.67 \\
& $(25.80)^{\mathrm{c}}$ \\
$M$ & 1.53 \\
& $(5.44)^{\mathrm{c}}$ \\
BR & -1.10 \\
& $(-1.86)^{\mathrm{a}}$ \\
LT & 0.01 \\
& $(2.74)^{\mathrm{c}}$ \\
SIZE & -0.22 \\
Samples & $(-10.34)^{\mathrm{c}}$ \\
$R^{2}$ & 1069 \\
\hline
\end{tabular}

Note: 1 . The $\mathrm{t}$ value. a, b, c represent the significance in $10 \%, 5 \%$, and $1 \%$ levels, respectively. 2. $A R 4, R, A I R, M, B R, L t$ and SIZErepresents dummy variable representing audit by the Big Four, market risk, average IR of individual share, 
market momentum, balling ratio, SIZE takes the natural logarithm of the offering size. 3. The t-ratio is reported in the parentheses.

The main cause of the dominance of the Snap-up Hypothesis in the mainland Chinese IPO market may be as follows: The auditing quality of local accounting firms in China is low (Lin and Lin, 2009; credit rating and certification center of the research institute of the Ministry of Commerce, 2013); comparatively, the credibility of the Big Four in China is high; the Big Four perform a low proportion of the IPO audits in China (market share of the Big Four in IPOs is only $3.74 \%$ ); finally, the balling ratio of IPOs in China is very low (only $1.20 \%$ in our study samples), which causes investors to snap up IPO shares from firms audited by the Big Four on the first day of listing. This leads to increased closing prices on the first day that greatly exceed offering prices, causing high IPO underpricing.

In this paper, the trading volumes and turnover ratio of the samples on the first day of listing are further collected, and the IPO firms audited by highly credible accounting firms are found to cause snap-up tide. The average trading volumes (turnover ratio) of IPO firms audited by the Big Four in bull and bear markets are 311,590,380 shares (15.01\%) and $27,942,517$ shares $(7.53 \%)$, respectively. These greatly exceed the average volumes of IPO firms audited by other accounting firms in bull and bear markets $(19,854,475$ shares (5.22\%) and 17,692,299 shares (3.13\%), respectively). The former average trading volumes are 15.69 (2.88) and 1.58 (2.41) times the latter average volumes, respectively. This indicates that the occurrence of the snap-up tide in mainland China.

Because of the previously mentioned snap-up tide and raised stock prices on the first day of listing, investors may actively subscribe shares of firms to be listed at the time of offering and then sell them on the first day of listing to obtain considerable profits.

\subsection{Robustness Tests}

To test the robustness of the previous empirical results, in this section the following robustness tests are performed: empirical analysis using market adjusted IR instead of raw IR as the dependent variable, analysis based on stock market division, analysis based on market states division, and analysis based on offering scale division. The test results are respectively shown in Table 4, Table 5, Table 6 and Table 7. It can be seen that the test results are close to the empirical results provided in previous section, without significant structural change. Thus, the conclusion of this study is robust.

Table 4. Empirical results using market adjusted IR as dependent variable

\begin{tabular}{ll}
\hline Dependent variable MRIR & \\
\hline $\mathrm{C}$ & 4.32 \\
& $(10.04)^{\mathrm{c}}$ \\
$A R 4$ & 0.63 \\
& $(6.90)^{\mathrm{c}}$ \\
RISK & 9.27 \\
& $(3.49)^{\mathrm{c}}$ \\
AIR & 0.67 \\
& $(25.80)^{\mathrm{c}}$ \\
$M$ & 0.53 \\
& $(1.88)^{\mathrm{a}}$ \\
BR & -1.10 \\
& $(-1.86)^{\mathrm{a}}$ \\
LT & 0.01 \\
& $(2.74)^{\mathrm{c}}$ \\
SIZE & -0.22 \\
Samples & $(-10.34)^{\mathrm{c}}$ \\
$\mathrm{R}^{2}$ & 1069 \\
\hline
\end{tabular}

Note: 1. Thistable replace raw IR with market adjusted IR as dependent variable on empirical analysis 2. Definition of the relevant explanatory variables refers the instructions of Table 3. 3. The t-ratio is reported in the parentheses.

In Table 4, market adjusted IR instead of raw IR is used as the dependent variable, and the results show that the coefficient of AR4 is 0.63, significant at the 1 per cent level. This result shows that hypothesis 2 is accepted. Thus, when market adjusted IR is used as $I R$, the empirical results also supports the hypothesis 2 , just like the analysis using raw IR as the dependent variable. 
Table 5. Empirical results of distinguishing different Listed Exchange

\begin{tabular}{lll}
\hline Dependent variable: $R I R$ & \\
\hline \multicolumn{2}{l}{ Market states Shanghai Stock Exchange Shengzhen } & Stock Exchange \\
$\mathrm{C}$ & 2.61 & 6.86 \\
& $(2.84)^{\mathrm{c}}$ & $(12.00)^{\mathrm{c}}$ \\
$A R 4$ & 0.28 & 0.78 \\
& $(2.41)^{\mathrm{b}}$ & $(4.86)^{\mathrm{c}}$ \\
$R I S K$ & 21.07 & 5.68 \\
& $(2.69)^{\mathrm{c}}$ & $(2.04)^{\mathrm{b}}$ \\
& 0.39 & 0.67 \\
& $(2.46)^{\mathrm{b}}$ & $(25.63)^{\mathrm{c}}$ \\
$M$ & 3.32 & 1.15 \\
& $(3.57)^{\mathrm{c}}$ & $(3.97)^{\mathrm{c}}$ \\
$B R$ & -3.36 & -0.45 \\
& $(-2.88)^{\mathrm{c}}$ & $(-0.67)$ \\
LT & -0.01 & 0.01 \\
& $(-0.85)$ & $(3.24)^{\mathrm{c}}$ \\
SIZE & -0.11 & -0.34 \\
Samples & $(-2.59)^{\mathrm{c}}$ & $(-12.28)^{\mathrm{c}}$ \\
$\mathrm{R}^{2}$ & 0.39 & 950 \\
\hline
\end{tabular}

Note: 1. Thistable divides samples listed in Shanghai Stock Exchange and ShenzhenStock Exchangeon empirical analysis.2. Definition of the relevant independent variables refers to the instructions of Table 3. 3. The t-ratio is reported in the parentheses.

In Table 5, the samples are divided into firms listed in Shanghai Stock Exchange and firms listed in Shenzhen Stock Exchange, and the results show that both the samples from Shanghai Stock Exchange and the samples from Shenzhen Stock Exchange support the Hypothesis 2, just like the results of Table 3. This indicates that the empirical results of this paper are independent of the stock exchange used.

Table 6. Empirical results of distinguishing different Market States

\begin{tabular}{lll}
\hline Dependent variable: RIR & \multicolumn{2}{l}{} \\
\hline Market States & \multicolumn{2}{l}{ Bull Market Bear Market } \\
$\mathrm{C}$ & 4.04 & 4.08 \\
& $(3.13)^{\mathrm{c}}$ & $(9.18)^{\mathrm{c}}$ \\
AR4 & 0.53 & 0.72 \\
& $(2.03)^{\mathrm{b}}$ & $(7.76)^{\mathrm{c}}$ \\
RISK & 13.61 & 8.37 \\
& $(1.53)$ & $(3.16)^{\mathrm{c}}$ \\
AIR & 0.62 & 0.63 \\
& $(12.34)^{\mathrm{c}}$ & $(16.57)^{\mathrm{c}}$ \\
$M$ & 0.42 & 0.12 \\
& $(0.51)$ & $(0.38)$ \\
$B R$ & -33.04 & -0.91 \\
& $(-3.29)^{\mathrm{c}}$ & $(-1.72)^{\mathrm{a}}$ \\
LT & -0.01 & 0.01 \\
& $(-0.80)$ & $(3.75)^{\mathrm{c}}$ \\
SIZE & -0.17 & -0.21 \\
Samples & $(-2.81)^{\mathrm{c}}$ & $(-9.49)^{\mathrm{c}}$ \\
$\mathrm{R}^{2}$ & 201 & 868 \\
\hline
\end{tabular}

Note: 1. This table divides the samples listed in bull market and bear market on empirical analysis. 2 . The way we dividing bull market and bear market in this paper refers to [3.3 Market states division Method]. 3. Definition of the relevant independent variables refers to the instructions of Table 3. 4. The t-ratio is reported in the parentheses.

In Table 6, the samples are divided into firms listed in bull market and bear market, and the results show that both coefficients are positive and significant, supporting the Hypothesis 2. This indicates that the empirical results of this paper are independent of the market states.

In Table 7, the samples are divided into firms of different scales, and the results show that all the three coefficients are positive and significant, supporting thehypothesis 2 . This indicates that the empirical results of this paper are independent of the scale of the listed firms. 
Table 7. Empirical results of distinguishing different offering size

\begin{tabular}{llll}
\hline Dependent variable: $R I R$ & \multicolumn{3}{l}{} \\
\hline Offering Size & \multicolumn{3}{l}{ Big Scale Medium Scale Small Scale } \\
$\mathrm{C}$ & -0.02 & 6.50 & 14.54 \\
& $(-0.02)$ & $(3.52)^{\mathrm{c}}$ & $(5.28)^{\mathrm{c}}$ \\
$A R 4$ & 0.21 & 1.24 & 2.28 \\
& $(2.59)^{\mathrm{c}}$ & $(2.63)^{\mathrm{c}}$ & $(5.73)^{\mathrm{c}}$ \\
RISK & 15.92 & 2.67 & 0.19 \\
& $(4.01)^{\mathrm{c}}$ & $(0.76)$ & $(0.03)$ \\
AIR & 0.53 & 0.57 & 0.65 \\
& $(11.71)^{\mathrm{c}}$ & $(15.31)^{\mathrm{c}}$ & $(13.04)^{\mathrm{c}}$ \\
$M$ & 2.32 & 1.48 & 0.73 \\
& $(5.95)^{\mathrm{c}}$ & $(4.07)^{\mathrm{c}}$ & $(1.25)$ \\
BR & -0.92 & -3.54 & -14.12 \\
& $(-2.02)^{\mathrm{b}}$ & $(-2.66)^{\mathrm{c}}$ & $(-2.33)^{\mathrm{b}}$ \\
LT & 0.01 & 0.01 & 0.02 \\
& $(1.35)$ & $(2.00)^{\mathrm{b}}$ & $(2.07)^{\mathrm{b}}$ \\
SIZE & -0.01 & -0.32 & -0.73 \\
& $(-0.31)$ & $(-3.50)^{\mathrm{c}}$ & $(-5.21)^{\mathrm{c}}$ \\
Samples & 321 & 428 & 320 \\
$\mathrm{R}^{2}$ & 0.49 & 0.50 & 0.62 \\
\hline
\end{tabular}

Note: 1. This table divides the samples to big scale, medium scale and small scale on empirical analysis. 2. In accordance with the offering size, we regard the biggest $30 \%$ offering size of all listed firms as the big scale, and middle $40 \%$ as the medium scale, smallest $30 \%$ as the small scale. 3 . Definition of the relevant independent variables refers the instructions of Table 3. 4. The t-ratio is reported in the parentheses.

\section{Conclusions and Suggestions}

This paper mainly exploresthe relation between IRs and audits by the Big Four. The sample period is from January 2007 to December 2012 (the new accounting standards in China is implemented in January 2007 for integrating with the international standards). The objects of this study are 1,069 IPO firms listed in the Shanghai and Shenzhen Stock Exchanges.

Many previous studies have proposed the Informational Hypothesis, which states that the IRs of initial public offerings (IPOs) being audited by the Big Four are lower than those IPOs being audited by other accounting firms. Oppositely, this paper proposes the Snap-up Hypothesis due to consider the IPOs in mainland China are characterized by "three lows,": the low reliability of audits being performed by non-Big Four, low proportion of IPOs audits being performed by the Big Four, and low balling ratio. These "three lows" features indicate that the Snap-up Hypothesis applies in the IPOs market of mainland China. In other words, the IRs of the IPOs being audited by the Big Four are higher than those IPOs being audited by other accounting firms due to the Big Four have the superior reputations.

As above mentioned, because the snap-up tide and raised stock prices on the first-day listing, investors may purchase the shares when offering and sell them on the first-day listing to obtain considerable profits.

This paper further collects the trading volumes and turnover ratio on the first day, and selects the Big Four audited IPOs by snap-up tide. For example, in the bullish market, the average volumes of IPOsbeing audited by the Big Four are $311,590,380$ shares, which is 15.69 times as large as others (19,854,475 shares).

To determine if the Snap-up Hypothesis is supportedin the IPO market of mainland China, several robustness tests are performed: empirical analysis using market adjusted IR rather than raw IR as the dependent variable as well as analyses based on exchange board division, market state division, and offering scale division. There is no significant structural change occurs on the test results. The conclusion regarding the dominance of the Snap-up Hypothesis is robust thus.

As above mentioned, because the snap-up tide and raised stock prices on the first-day listing, investors may purchase the shares when offering and sell them on the first-day listing to obtain considerable profits.

\section{References}

Balvers, R. J., McDonald, B., \& Miller, R. (1988). Underpricingof New Issues and the Choice of Auditors as a SignalofInvestment Banker Reputation. The Accounting Review, 63, 605-622.

Beatty, R. P. (1989). Auditor reputation and the pricing of initial public offerings. Accounting Review, 64 (4), 693-709.

Beatty, R. P., \& Ritter, J. (1986). Investment banking, reputation, and the underpricing ofinitial public offerings, Journal of Financial Economics, 15, 213-233. https://doi.org/10.1016/0304-405X(86)90055-3

Cai, Y. Q., Ni, B. H., Huang, M. Z., \& Liao, L. M. (2008). Audit fee and pricing in Chinese Mainland: a empirical study on the listed companies in Shenzhen Stock Exchange. Journal of Soochow Economic and Business, 63, 1-28. 
Chan, K., Wang, J., \& Wei, K. C. J. (2004). Underpricing and Long-Term Performance of IPOs in China, Journal of Corporate Finance, 10, 409-430. https://doi.org/10.1016/S0929-1199(03)00023-3

Chang, X., Gygax, A. F., Oon, E., \& Zhang, H. F. (2008). Audit quality, auditor compensation and initial public offering underpricing. Accounting and Finance, 48, 391-416. https://doi.org/10.1111/j.1467-629X.2008.00275.x

Chen, G., Firth, M., \& Kim, J. B. (2004). IPO underpricing in China's new stock markets. Journal of Multinational Financial Management, 14(3), 283-302. https://doi.org/10.1016/j.mulfin.2003.07.007

Chen, H. M., \& Li, D. (2004). A positive research on the hypothesis of the certified accountant off ices reputation of short-run underpricing on the stocks of IPO in China. Audit and Economy Research, 1, 26-29(in Chinese).

Chi, J., \& Padgett, C. (2005). The performance and long-run characteristics of the Chinese IPO market.Pacific Economic Review, 10(4), 451-469. https://doi.org/10.1111/j.1468-0106.2005.00285.x

Derrien, F., \& Womack, K. L. (2003). Auctions vs. bookbuilding and the control of underpricing in hot IPO markets. Review of Financial Studies, 16(1), 31-61. https://doi.org/10.1093/rfs/16.1.0031

Edwards, S., Biscarri, J. G., \& Pérez de Gracia, F. (2003). Stock market cycles, financial liberalization and volatility. Journal of International Money and Finance, 22(7), 925-955.https://doi.org/10.1016/j.jimonfin.2003.09.011

Fan, J. P. H., \& Wong, T. J. (2005). Do External Auditors Performa Corporate Governance Role in Emerging Markets? Evidence from East Asia. Journal of Accounting Research, 43, 35-72. https://doi.org/10.1111/j.1475-679x.2004.00162.x

Ferri, G., \& Liu, L. G. (2010). Honor thy creditorsbefore thyshareholders: are the profits of Chinese state $=$ owned enterprises real? Asian Economic Papers, 9(3), 50-71. https://doi.org/10.1162/ASEP_a_00025

Frankel, R., Johnson, M., \& Nelson, K. (2002). The relation between auditors' fees for nonaudit services and earnings management. The Accounting Review, 77, 71-105. https://doi.org/10.2308/accr.2002.77.s-1.71

Gao, Y. (2010). What comprises IPO initial returns: Evidence from the Chinese market.Pacific-Basin Finance Journal, 18(1), 77-89. https://doi.org/10.1016/j.pacfin.2009.08.001

Hamilton, W. P. (1919). Stock market analysis, Wall StreetJournal, 9 (August) (Reprinted in Rhea, R. (1932).The Dow Theory, Barron's, New York, pp. 181-2).

Holland, K. M., \& Horton, J. G. (1993). Initial PublicOfferings on the Unlisted Securities Market: The Impact of ProfessionalADvisers. Accounting and Business Research, 24(93), 19-34. https://doi.org/10.1080/00014788.1993.9729461

Hu, D., \& Feng, Q. G. (2013). Information environment, audit quality and IPO underpricing: based on the A-share IPO firms during 2009 2011. Accounting Research, 2013, 2, 78-95.

Katsenelson, V. N. (2007). Active Value Investing: Making Money in Range Bound Markets, John Wiley and Sons, Inc Publishing, New York, NY.

Kunz, R. M., \& Aggarwal, R. (1994). Why initial public offerings are underpriced: Evidence from Switzerland. Journal of Banking \& Finance, 18(4), 705-723. https://doi.org/10.1016/0378-4266(93)00016-I

Lee, J. S., Kuo, C. T., \& Yen, P. H. (2011). Market States and Initial Returns: Evidence from Taiwan IPOs.Emerging Markets Finance and Trade, 47(2), 6-20. https://doi.org/10.2753/REE1540-496X470201

Lee, J. S., Yen, P. H., \& Chan, K. C. (2013). Market States and Disposition Effect: Evidence from Taiwan Mutual Fund Investors. Applied Economics, 45(10), 1331-1342. https://doi.org/10.1080/00036846.2011.617696

Lee, W. Y., Jiang, C. X., \& Indro, D. C. (2002). Stock market volatility, excess returns, and the role of investor sentiment. Journal of Banking \& Finance, 26(12), 2277-2299. https://doi.org/10.1016/S0378-4266(01)00202-3

Lin, C. J., \& Lin, X. L. (2009). Does auditor reputation affect equity pricing: the evidence from IPO marketization? Accounting Review, 49, 67-72.

Liu, W., \& Tan, Z. Y. (2009). Empirical Study on signal transmission of auditor reputation. Friends of Accounting, 11, 105-107.

Ljungqvist, A., Nanda, V., \& Singh, R. (2001). Hot markets, investor sentiment, and IPO pricing. Journal of Business, 79(4), 1667-1702. https://doi.org/10.1086/503644

Loughran, T., \& Ritter, J. R. (2002). Why don't issuers get upset about leaving money on the table in IPOs? Review of Financial Studies, 15(2), 413-444. https://doi.org/10.1093/rfs/15.2.413

Lyn, E. O., \& Zychowicz, E. J. (2003) .The performance of new equity offerings in Hungary and Poland. Global 
Finance Journal, 14(2), 181-195. https://doi.org/10.1016/S1044-0283(03)00011-5

Michaely, R., \& Shaw, W. H. (1995). Does the choice of auditor convey quality in an initial public offering? Financial Management, 15-30. https://doi.org/10.2307/3665948

Pagan, A. R., \& Sossounov, K. A. (2003). A simpleframework for analyzing bull and bear markets. Journal of Applied Econometrics, 18, 23-46. https://doi.org/10.1002/jae.664

Qiu, D. Y., Peng, H., \& Yao, Y. (2013). Auditor reputation and IPOs underpricing: An empirical study based on SME board market. Fujian Tribune(The Humanities \& Social Sciences Monthly),8, 36-43.

Rock, K. (1986). Why new issues are underpriced, Journal of FinancialEconomics, 15, 187-212. https://doi.org/10.1016/0304-405X(86)90054-1

Song, S. L., Tan, J. S., \& Yi, Y. (2014). IPO initial returns in China: Underpricing or overvaluation? China Journal of Accounting Research, 7, 31-49. https://doi.org/10.1016/j.cjar.2013.12.001

$\mathrm{Su}$, D., \& Fleisher, B. M. (1999). An empirical investigation of underpricing in Chinese IPOs. Pacific-Basin Finance Journal, 7(2), 173-202. https://doi.org/10.1016/S0927-538X(99)00005-0

Teoh, S. H., \& Wong, T. J. (1993). Perceived auditor quality and the earnings response coefficient.Accounting Review, 346-366.

The Credit Rating and Certification Center of the Research Institute of the Ministry of Commerce. (2013). According to the Appraisal Report on Financial Safety of Non-financial Listed Firms in China in 2013.

The Credit Rating and Certification Center of the Research Institute of the Ministry of Commerce. (2014). According to the Appraisal Report on Financial Safety of Non-financial Listed Firms in China in 2014.

Tian, L. H. (2011). Regulatory underpricing: Determinants of Chinese extreme IPO returns. Journal of Empirical Finance, 18, 78-90. https://doi.org/10.1016/j.jempfin.2010.10.004

Wang, B., Xin, Q. Q., \& Yang, D. M. (2009). Whether auditor reputation influences share pricing: evidence from IPO market in China. Accounting Research, 11, 73-81.

Wang, L., \& Zhang, J. T. (2005). Empirical study on the phenomenon of IPO underpricing in Shanghai A-share market. Market Modernization, 26, 101-117.

Yang, S., Wang, T., \& Jiang, S. (2007) .What Explains the High Returns to the IPOs of China's A - Shares? Journal of Economic Policy Reform, 10(4), 297-308. https://doi.org/10.1080/17487870701552012

Zeng, X. Y., \& Shi, S. (2011). The effect of accounting firms to IPO pricing. Management Engineer, 5, 29-31.

\section{Copyrights}

Copyright for this article is retained by the author(s), with first publication rights granted to the journal.

This is an open-access article distributed under the terms and conditions of the Creative Commons Attribution license which permits unrestricted use, distribution, and reproduction in any medium, provided the original work is properly cited. 